\title{
LA-UR-15-26220
}

Approved for public release; distribution is unlimited.

Title: $\quad$ synthesis of selenium- and tellurium-containing tryptophan analogs for the elucidation of protein structure and function

Author(s): $\quad$ Hatch, Duane M

Intended for: $\quad$ Report

Issued: 
Disclaimer:

Los Alamos National Laboratory, an affirmative action/equal opportunity employer,is operated by the Los Alamos National Security, LLC for the National NuclearSecurity Administration of the U.S. Department of Energy under contract DE-AC52-06NA25396. By approving this article, the publisher recognizes that the U.S. Government retains nonexclusive, royalty-free license to publish or reproduce the published form of this contribution, or to allow others to do so, for U.S. Government purposes. Los Alamos National Laboratory requests that the publisher identify this article as work performed under the auspices of the U.S. Departmentof Energy. Los Alamos National Laboratory strongly supports academic freedom and a researcher's right to publish; as an institution, however, the Laboratory does not endorse the viewpoint of a publication or guarantee its technical correctness. 


\section{Synthesis of Selenium- and Tellurium-Containing Tryptophan Analogs for the Elucidation of Protein Structure and Function}

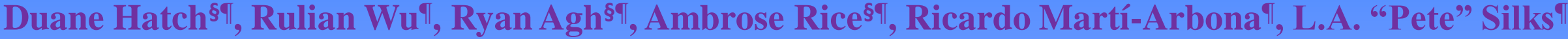

IBioscience Division, Group B11, Los Alamos National Laboratory, Los Alamos, NM, 87545

${ }^{\S}$ Department of Chemistry \& Physics, Belmont University, Nashville, TN, 37212

$$
\text { July 14, } 2015
$$<smiles>NC(Cc1c[nH]c2[se]ccc12)C(=O)O</smiles>

4-(6H-selenolo[2,3-b]pyrrolyl)-L-alanine $[6,7]$ SeTrp

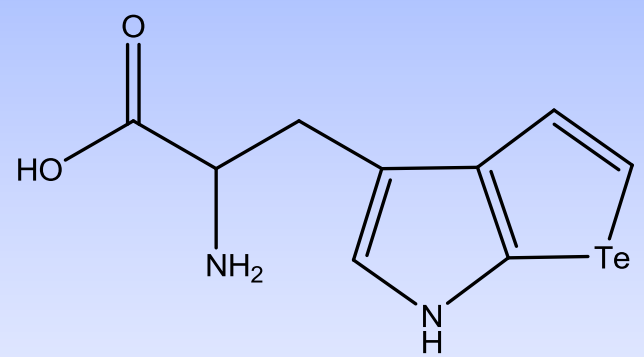

4-(6H-telluro[2,3-b]pyrrolyl)-L-alanine $[6,7]$ TeTrp<smiles>NC(Cc1c[nH]c2ccccc12)C(=O)O</smiles> 
- B.S. Biochemistry, TTU, 2001.

- M.S. Chemistry, TTU, 2003.

- GRA, Bioscience Division, LANL, 2002-2004.

- Ph.D., Organic Synthesis, University of Cincinnati, 2009.

- NIH Post-doctoral Fellow, Vanderbilt University, 20092011.

- Visiting Scholar, Vanderbilt University, 2011-2015.

- Assistant Professor, Chemistry, Belmont University, 2011current.

- Guest Scientist, Bioscience Division, LANL, 2014-current. 


\section{Goals}

- Rational design, synthesis, and characterization of Se- and Tecontaining tryptophan analogs.

- Synthesis of selenonphenes and tellurophenes

- Enzymatic coupling of serine side chain using tryptophan synthase

- Bio-incorporate heavy atom tryptophan analogs into selected proteins.

- X-ray and NMR structural studies of selected proteins.

- Rationally design drugs based off active sites and other functionally important protein residues.

- Design novel proteins that have new functional properties. 


\section{Methods of solving protein structures}

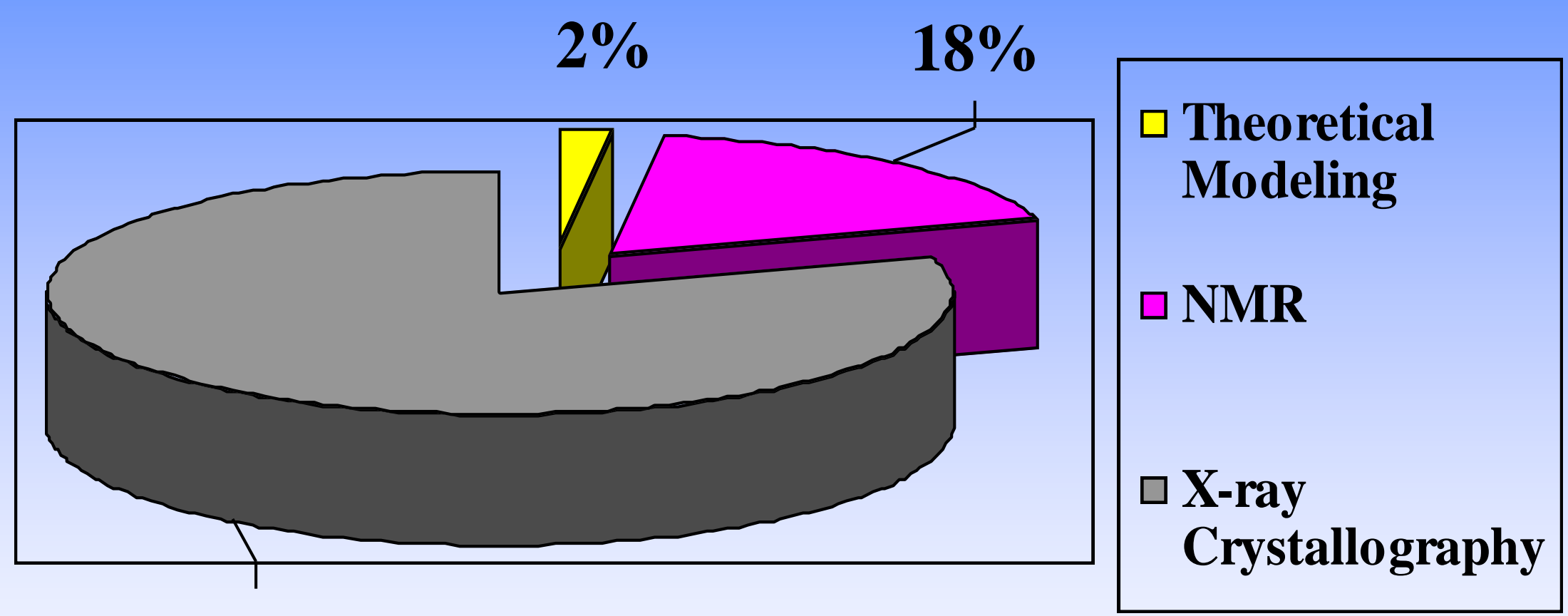

$80 \%$

*Percentages based on current Protein Data Bank entries 


\section{Methods continued}

- X-ray crystallography

- Molecular replacement (MR) - homologous protein with $>40 \%$ sequence identity.

- Isomorphous replacement (SIR/MIR) - soak crystals in salts of heavy atoms and compare diffraction patterns to native crystal (deduce phases). (often changes cell dimensions)

- Multiwavelength anomalous dispersion (MAD) SeMet

- Single anomalous dispersion (SAD) - SeMet

- NMR

- SOLVE/RESOLVE - computational 
Overview of the X-ray Crystallographic Method
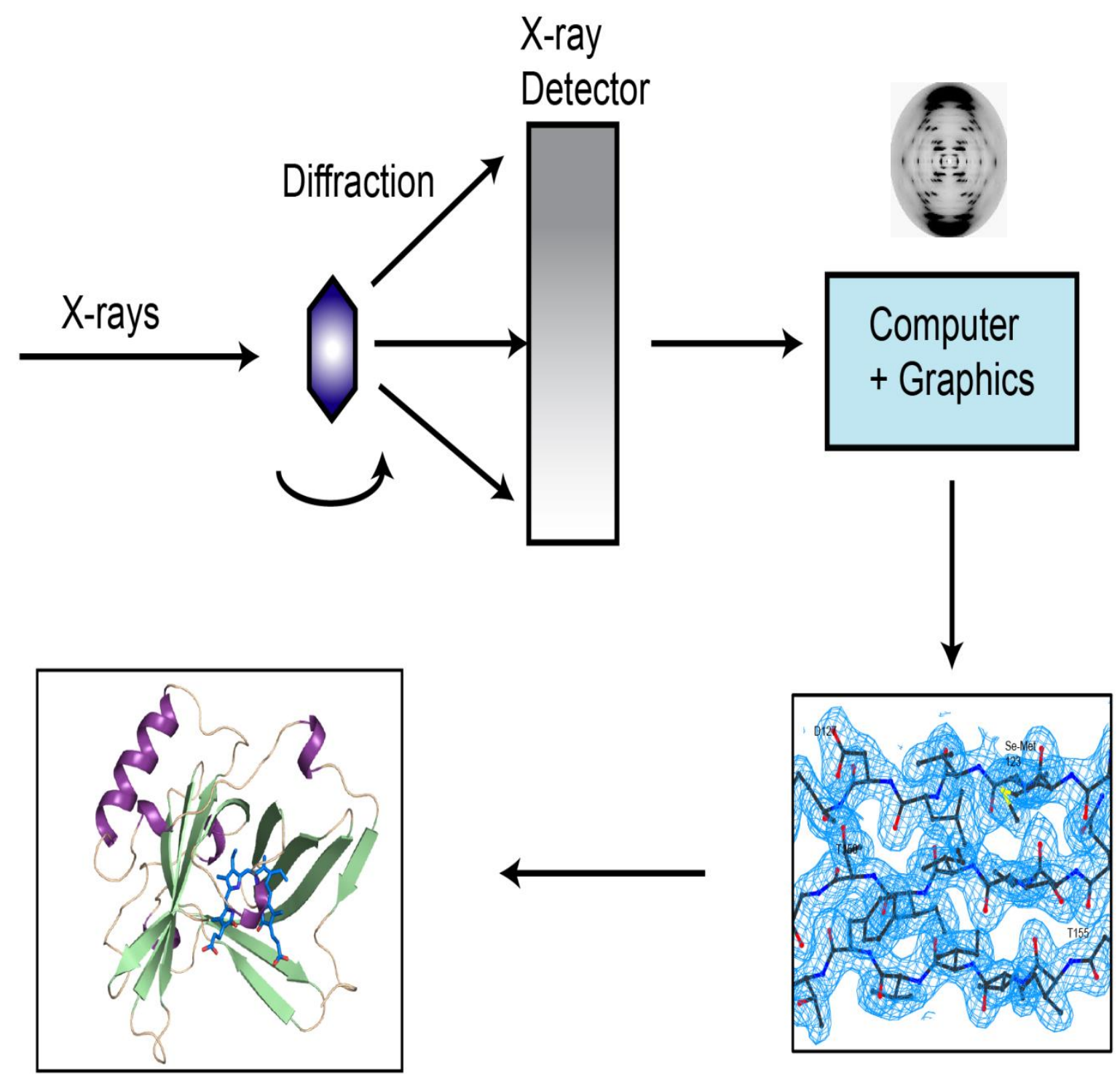

Protein Model

Electron Density Map 


\section{The "phase problem" of x-ray crystallography}

-X-ray diffraction patterns from crystals of proteins contain sufficient information to define atomic structure.

- Atomic positions are inextricable without having electron-density images.

- Diffraction measurements provide amplitudes (probability proportional to the square of the amplitude of this wave), but not phases for the diffracted waves, which is needed for the computation of electron density.

- Phase problem is reduced by determining the position of a few heavy atoms (anomalous scattering or dispersion).

- Different atoms contribute to the scattered intensity in proportion to the square of the number of electrons they contain. 


\section{A solution to the "phase problem"}

- Develop heavy atom (electron rich) containing amino acids (Se- and Te-containing tryptophan analogs).

- The MAD technique yields anomalous scattering of the electron rich metalloid atoms, thus allowing the phases to be determined from a single crystalline species.

- Selenomethionine (SeMet) is the gold standard. 


\section{Use of selenomethionine (SeMet)}
Web of Science TM
InCites $\mathrm{TM}$
Journal Citation Reports ${ }^{\circledR}$
Essential Science Indicators sm
EndNote TM
\begin{tabular}{l|l|l} 
Sign In $\checkmark$ & Help & English $~$
\end{tabular}
WEB OF SCIENCE
THOMSON REUTERS

Search

Results: 677

(from All Databases)

You searched for: TOPIC:

(selenomethionine) ....More

\section{Refine Results}

Search within results for...

Databases

4

Research Domains

$\square$ SCIENCE TECHNOLOGY

$\square$ SOCIAL SCIENCES
Sort by:

Publication Date -- newest to oldest
My Tools - Search History Marked List 


\section{Ideal heavy atom derivative}

- Stability is important both chemically and structurally.

- SeMet and TeMet are prone to oxidation (no longer useful).

- SeTrp and TeTrp should be more stable as the heavy atom is part of an aromatic ring system.

Low frequency of occurrence in the asymmetric unit.

- Phase determination generally fails if more than $\sim 4$ heavy atoms are present in the repeating unit of the crystal.

- Methonine is the $4^{\text {th }}$ most rare AA $(2.6 \%)$.

- Tryptophan is the most rare AA (1.3\%).

- Applicable to a larger range of proteins.

Se-77 and Te-125 are NMR active isotopes (large chemical shifts that are highly sensitive to the local structural environment).

- Use SeTrp and TeTrp alongside SeMet (more tools in the toolbox). 


\section{Syntheses of selenophene pyrroles}

- 1 st reported synthesis for selenolo[3,2- $b]$ pyrrole and selenolo[2,3- $b]$ pyrrole were published by Paulmier and coworkers in 1978.

- More recent attempts to improve the $35 \%$ and $38 \%$ yields were carried out by Phillips and coworkers in 1999.

- The selenophene pyrroles were constructed through slight modifications of the final step of Paulmier's original method. 


\section{Phillips modified Paulmier method for the construction of}

\section{4-(6H-selenolo[2,3-b]pyrrolyl)-L-alanine}

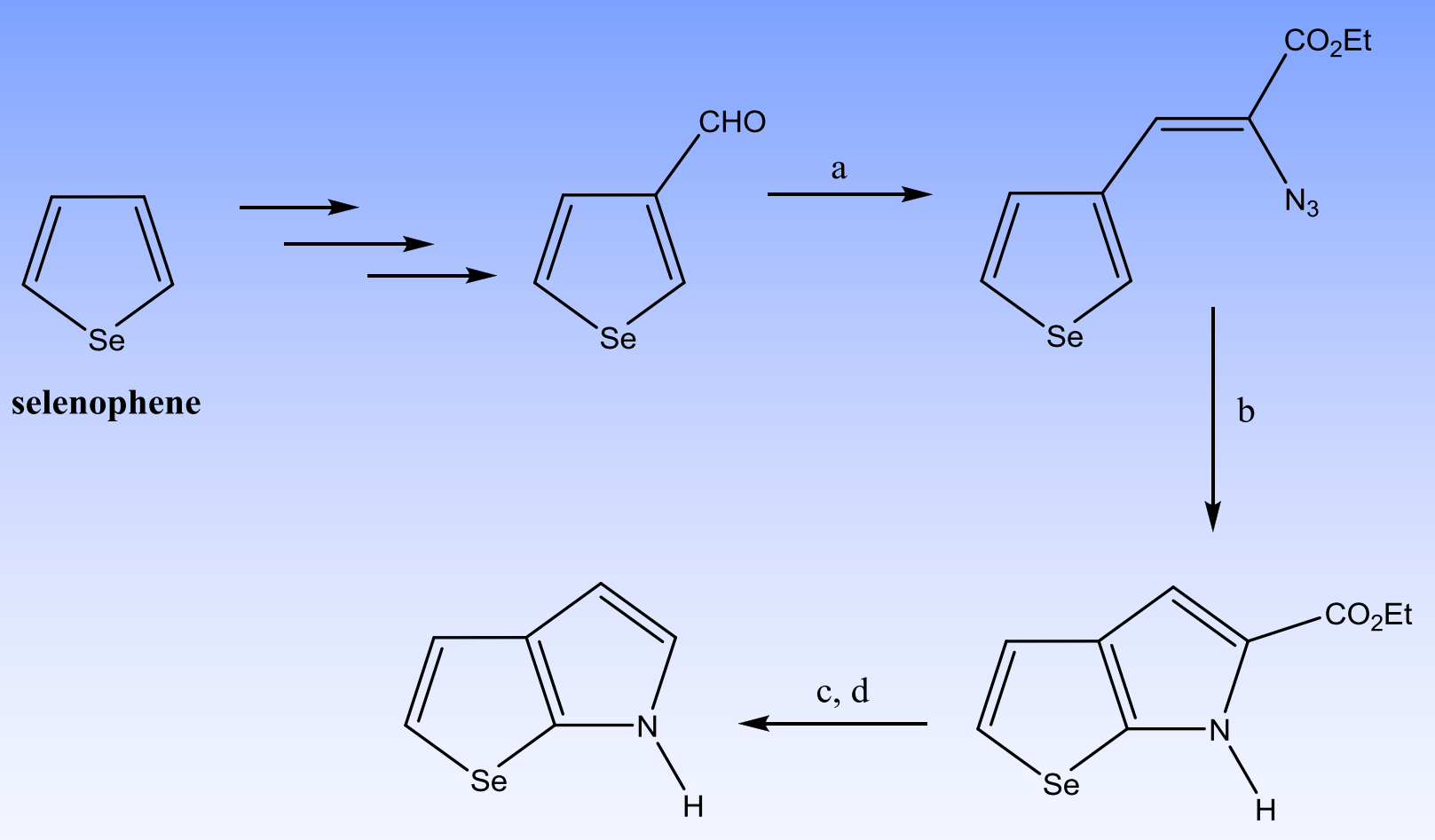

Reagents: (a) $\mathrm{N}_{3} \mathrm{CH}_{2} \mathrm{CO}_{2} \mathrm{Et}, \mathrm{NaOEt}, \mathrm{O}^{\circ} \mathrm{C}, 2 \mathrm{~h}(60 \%)$; (b) xylenes, reflux, $10 \mathrm{~min}$, (crude yield 85\%); (c) KOH, heat (crude yield 100\%); (d) glycerol, $160-170^{\circ} \mathrm{C}, 45$ min (crude yield $75 \%$ ). Phillips et al., 1999. 


\section{Phillips modified Paulmier method for the construction of}

\section{6-(4H-selenolo[3,2-b]pyrrolyl)-L-alanine}

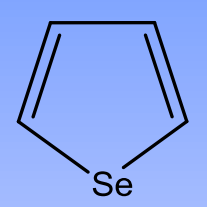

selenophene

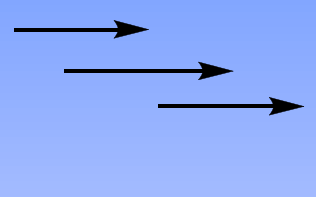

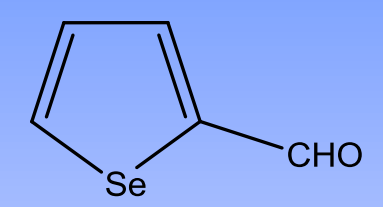

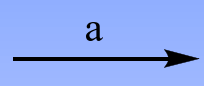

c, d
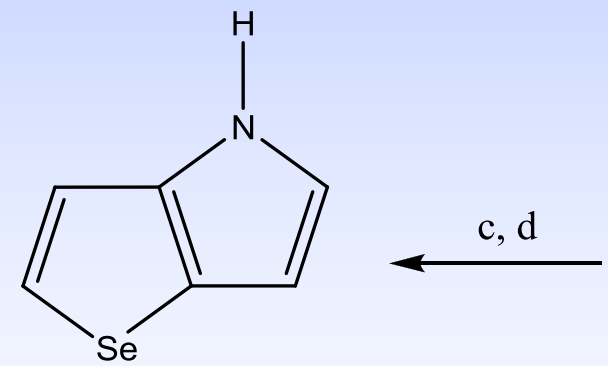

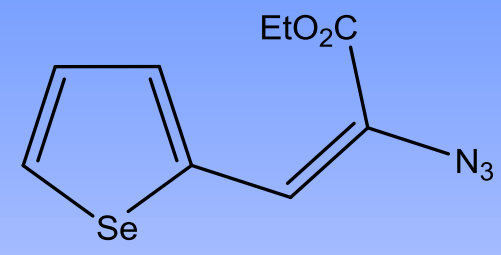

Reagents: (a) $\mathrm{N}_{3} \mathrm{CH}_{2} \mathrm{CO}_{2} \mathrm{Et}, \mathrm{NaOEt}, \mathrm{O}^{\circ} \mathrm{C}, 2 \mathrm{~h}(55 \%)$; (b) xylenes, reflux, $10 \mathrm{~min}$, (crude yield 85\%); (c) $\mathrm{KOH}$, heat (crude yield 100\%); (d) glycerol, $160-170^{\circ} \mathrm{C}, 45$ min (crude yield 70\%). Phillips et al., 1999. 


\section{Old synthesis of [6,7]SeTrp; LANL}
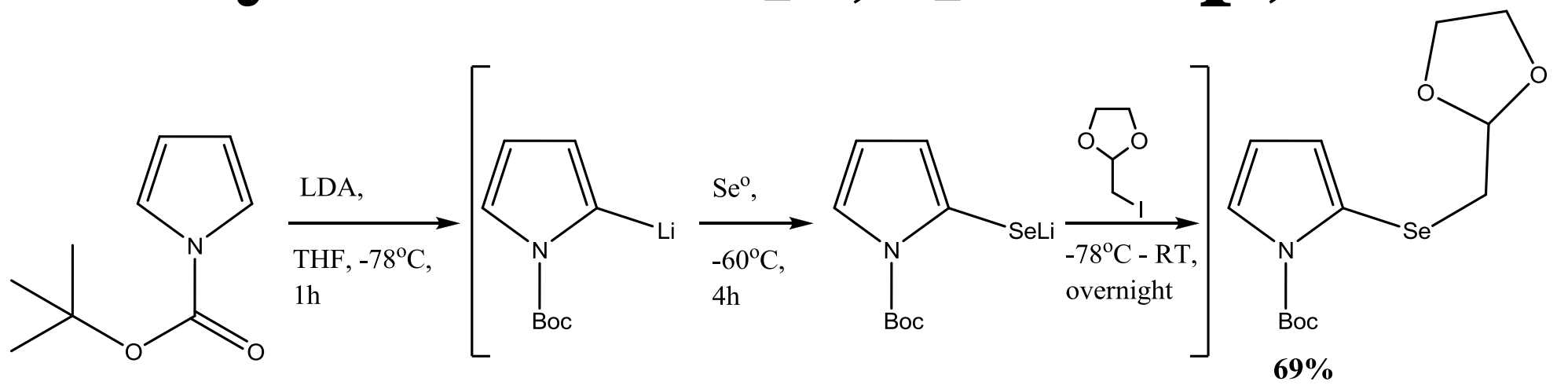

N-Boc-pyrrole

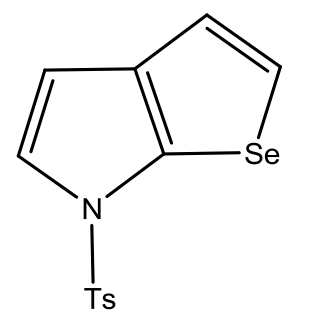

$72 \%$ with

Amberlyst-15

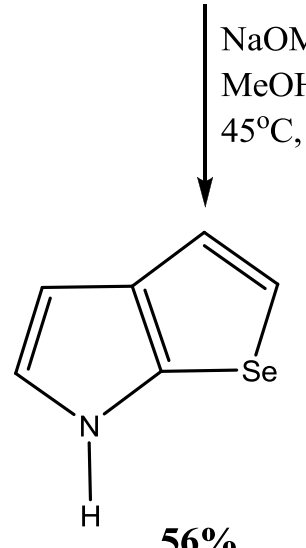

$\mathrm{NaOMe}$,

$\mathrm{eOH}$

$5^{\circ} \mathrm{C}$, overnight

tyrptophan synthase, PLP

L-serine, $\mathrm{K}_{2} \mathrm{HPO}_{4}$ buffer pH $7.8,37^{\circ} \mathrm{C}$

$56 \%$
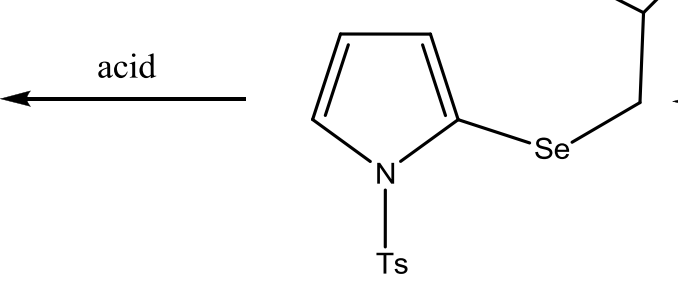

a. $\mathrm{NaH}, \mathrm{THF}$ $\longleftarrow 0^{\circ} \mathrm{C}, 2 \mathrm{~h}$

b. $\mathrm{TsCl}, 0^{\circ} \mathrm{C}-\mathrm{RT}$, overnight

$85 \%$ over two steps

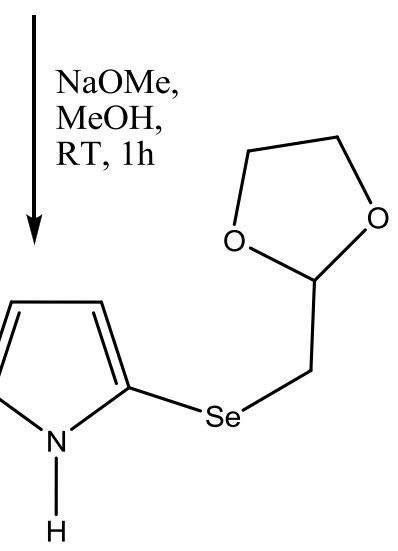

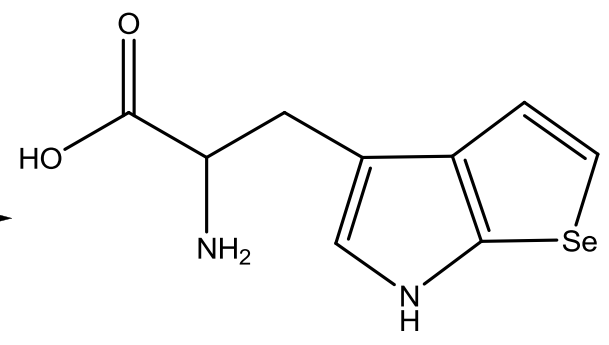

$[6,7]$ SeTrp
Boles et al., 2002

Hatch, 2003

Hatch et al., 2004 


\section{Annulation data for various Lewis acids}

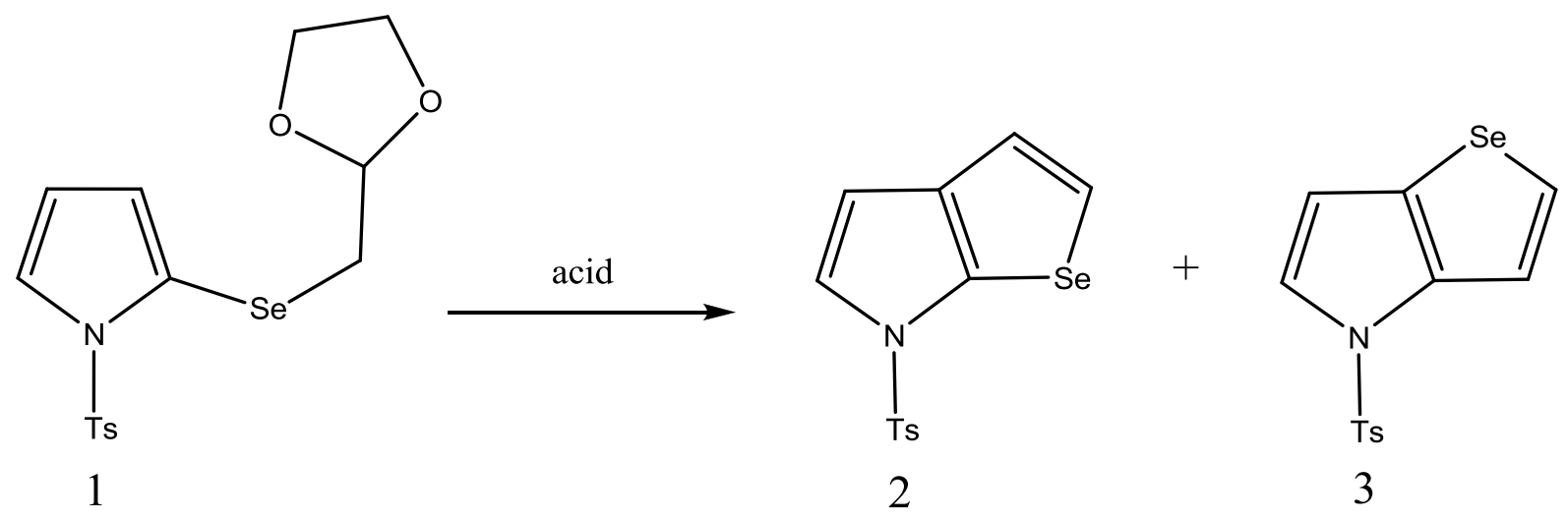

\begin{tabular}{|c|c|c|c|}
\hline Acid & Conditions $^{\text {a }}$ & Yield of 2 & Yield of 3 \\
\hline Amberlyst & Reflux $24 \mathrm{hr}$. & $72^{\mathrm{c}}$ & 5 \\
\hline $\mathrm{TiCl}_{4}$ & $-78^{\circ} \mathrm{C}$ & $48^{\mathrm{b}}$ & 0 \\
\hline $\mathrm{TiCl}_{2}(\mathrm{O} \text {-isopropy })_{2}$ & $-78^{\circ} \mathrm{C}$ to RT & $58^{\mathrm{b}}$ & 0 \\
\hline $\mathrm{TiCl}_{2}(\mathrm{O} \text {-isopropy })_{2}$ & $-78^{\circ} \mathrm{C}$ to $-10^{\circ} \mathrm{C}$ & $21^{\mathrm{c}}$ & 0 \\
\hline $\mathrm{TiCl}_{2}(\text { butoxide })_{2}$ & $-78^{\circ} \mathrm{C}$ & $0^{\mathrm{b}}$ & 0 \\
\hline $\mathrm{BF}_{3}$ & $-78^{\circ} \mathrm{C}$ to $-55^{\circ} \mathrm{C}$ & $0^{\mathrm{b}}$ & 0 \\
\hline $\mathrm{SnCl}_{4}$ & $-78^{\circ} \mathrm{C}$ to RT & $0^{\mathrm{b}}$ & 0 \\
\hline $\mathrm{ZnCl}_{2}$ & $-20^{\circ} \mathrm{C}$ to RT & $0^{\mathrm{b}}$ & 0 \\
\hline
\end{tabular}

a) No starting material recovery yields were obtained for the above reactions. b) Small scale reaction. c) Performed on $4.75 \mathrm{~g}$. 


\section{New synthesis of $[6,7]$ SeTrp; LANL}

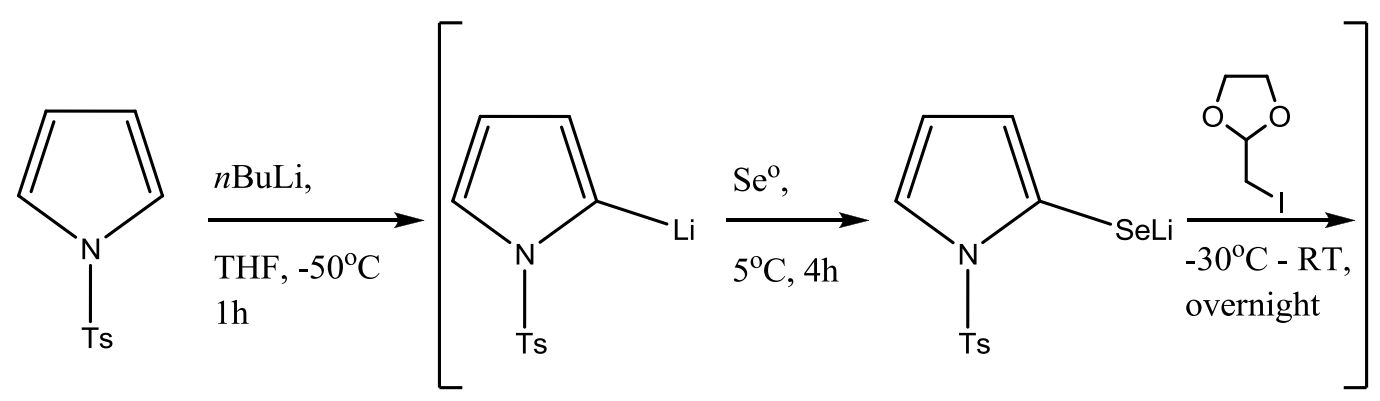

N-Tosyl-pyrrole

Note: $\mathrm{Te}^{\mathbf{0}}$ can also be used to

make $[6,7]$ TeTrp<smiles>NC(Cc1c[nH]c2[se]ccc12)C(=O)O</smiles>

$[6,7]$ SeTrp or $[6,7]$ TeTrp tyrptophan synthase, PLP,

L-serine, $\mathrm{K}_{2} \mathrm{HPO}_{4}$ buffer pH $7.8,37^{\circ} \mathrm{C}$

Note: stable isotope labeled L-serine side chains can be used during the enzymatic coupling.
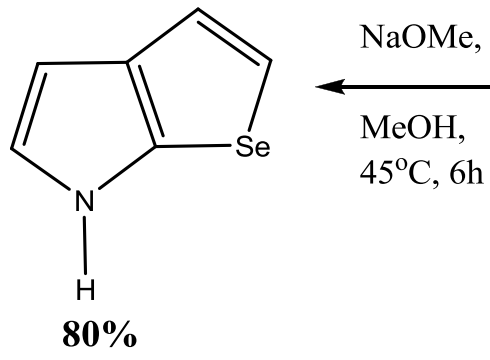

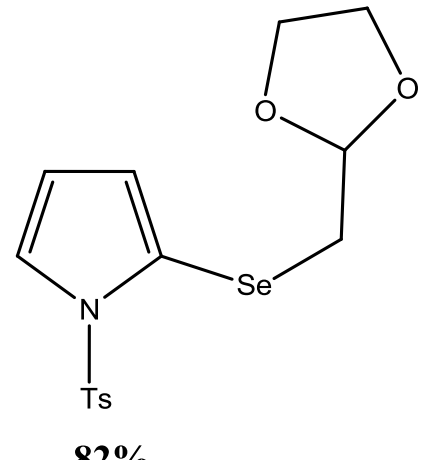

$82 \%$
$\mathrm{ZnCl}_{2}$-clay, $\mathrm{PhCl}$, reflux, $30 \mathrm{~min}$

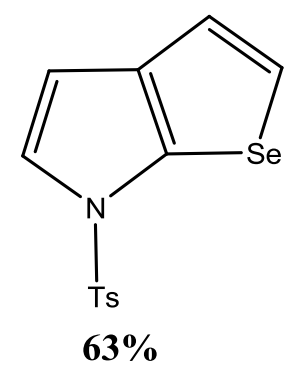

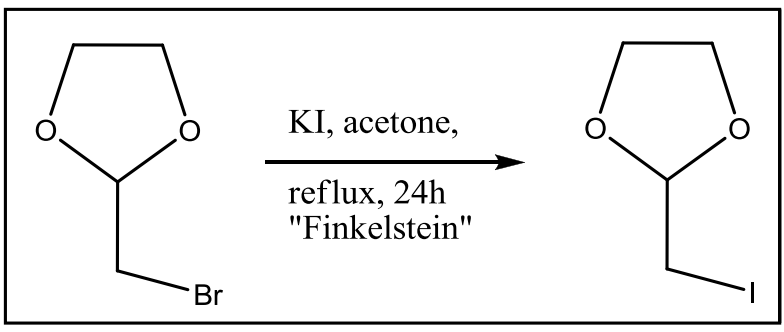


Table 2.6. ${ }^{1} \mathrm{H}$-NMR Ts-selenide data.

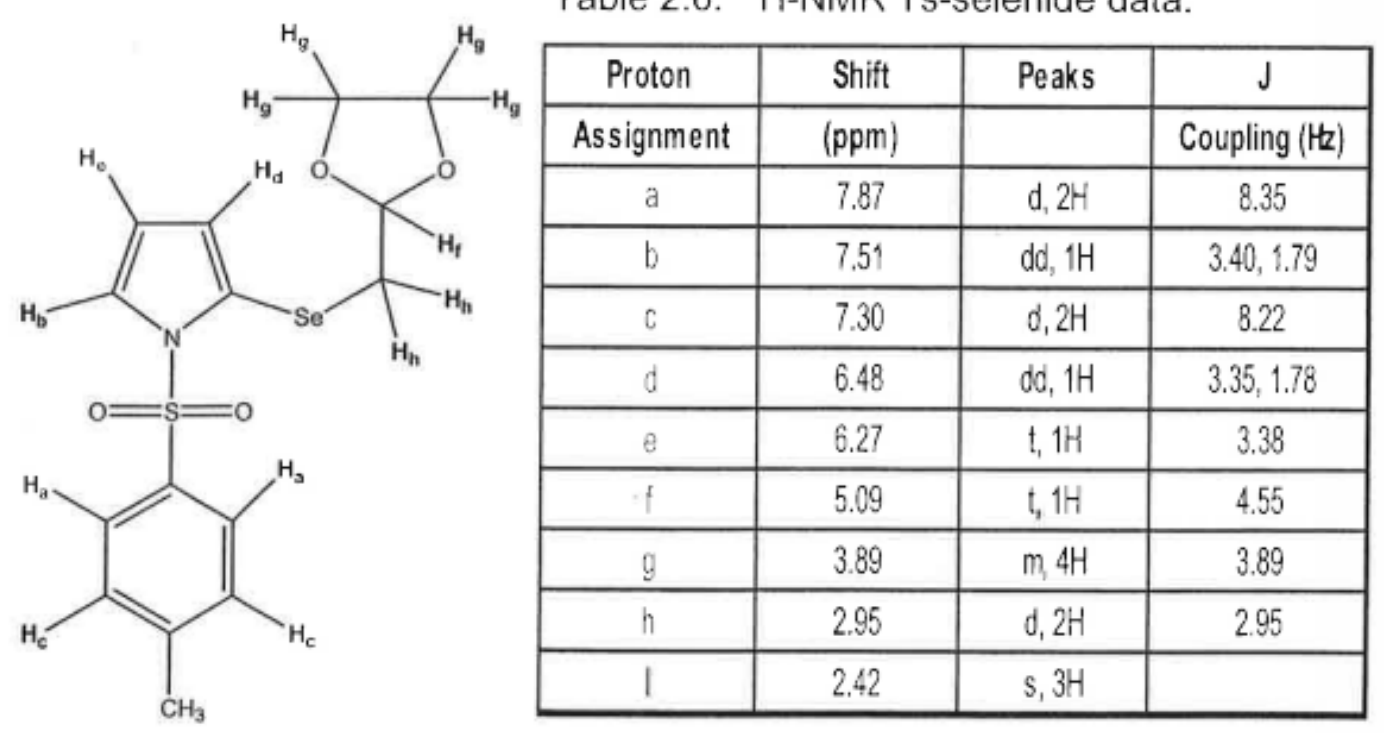

I2 - procegalng f:zanotara SI.

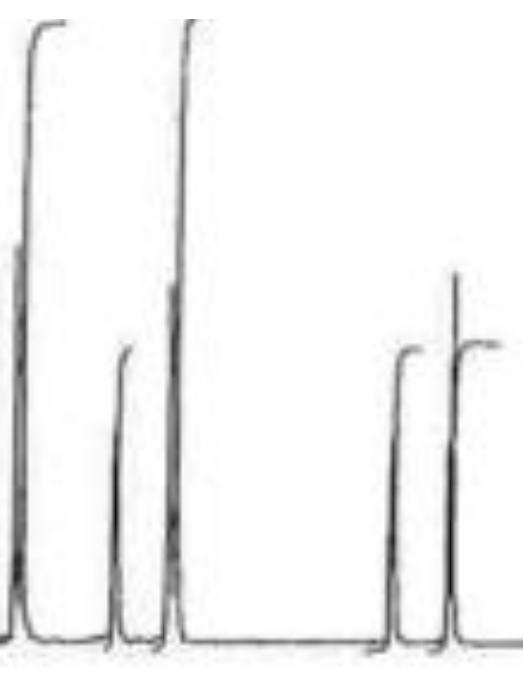

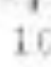

9

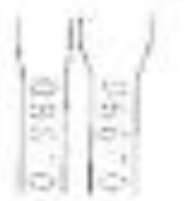

6

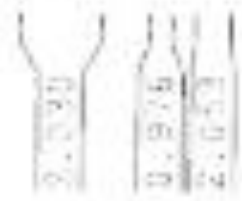

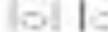





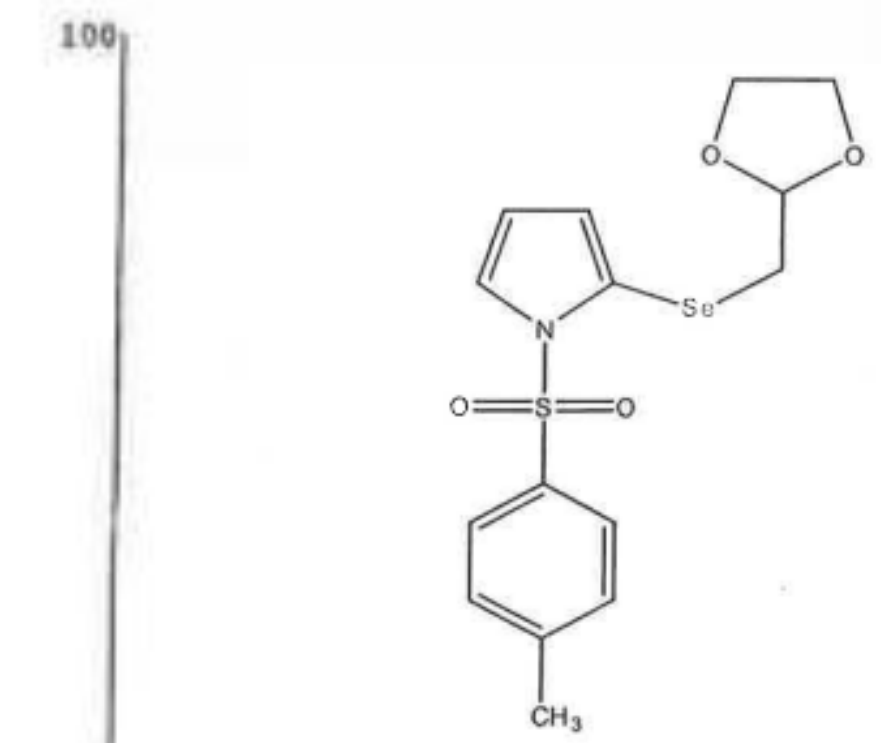

$\mathrm{C}_{15} \mathrm{H}_{17} \mathrm{NO}_{4} \mathrm{SSe}$

Exact Mass: 387.00

Mol. Wt.: 386.33

C. $46.63 ; \mathrm{H}, 4.44 ; \mathrm{N}, 3.63 ; \mathrm{O}, 16.57 ; \mathrm{S}, 8.30 ; \mathrm{Se}, 20.44$

2x+1․, 1

386,2

\section{2}

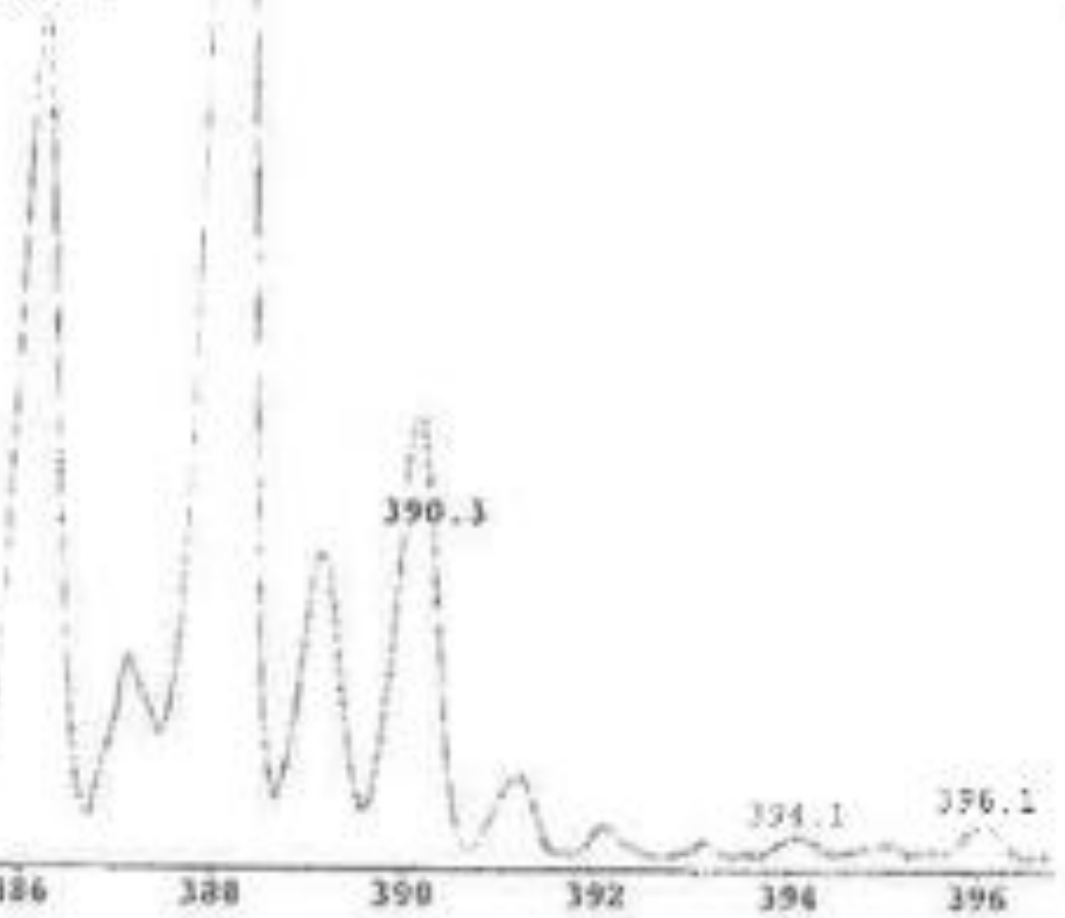




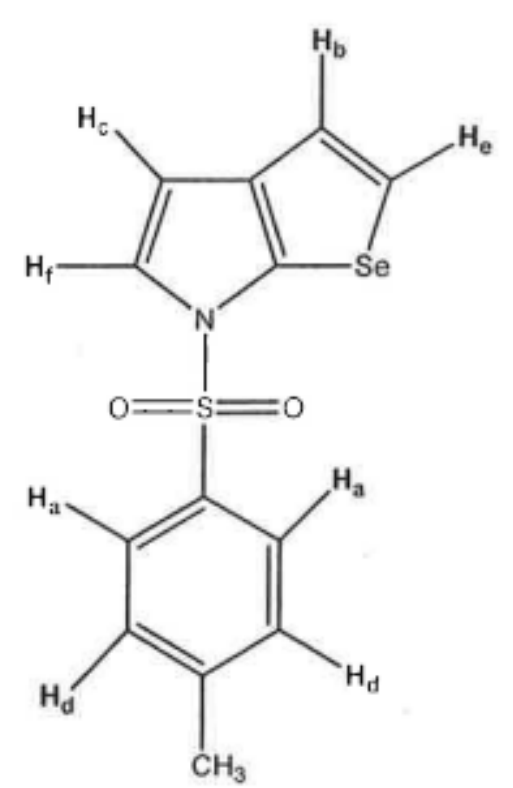

Table 2.8. ${ }^{1} \mathrm{H}-\mathrm{NMR}$ Ts-Heterocycle data.

\begin{tabular}{|c|c|c|c|}
\hline Proton & Shift & Peaks & J \\
\hline Assignment & $(\mathrm{ppm})$ & & Coupling (Hz) \\
\hline $\mathrm{a}$ & 7.87 & $\mathrm{~d}, 2 \mathrm{H}$ & 8.57 \\
\hline$b$ & 7.61 & $\mathrm{dd}, 1 \mathrm{H}$ & $5.79,0.92$ \\
\hline $\mathrm{c}$ & 7.34 & $\mathrm{dd}, 1 \mathrm{H}$ & $3.40,0.91$ \\
\hline $\mathrm{d}$ & 7.29 & $\mathrm{~d}, 2 \mathrm{H}$ & 8.31 \\
\hline $\mathrm{e}$ & 7.19 & $\mathrm{~d}, 1 \mathrm{H}$ & 5.79 \\
\hline $\mathrm{t}$ & 6.62 & $\mathrm{~d}, 1 \mathrm{H}$ & 3.39 \\
\hline $\mathrm{g}$ & 2.40 & $\mathrm{~s}, 3 \mathrm{H}$ & \\
\hline
\end{tabular}
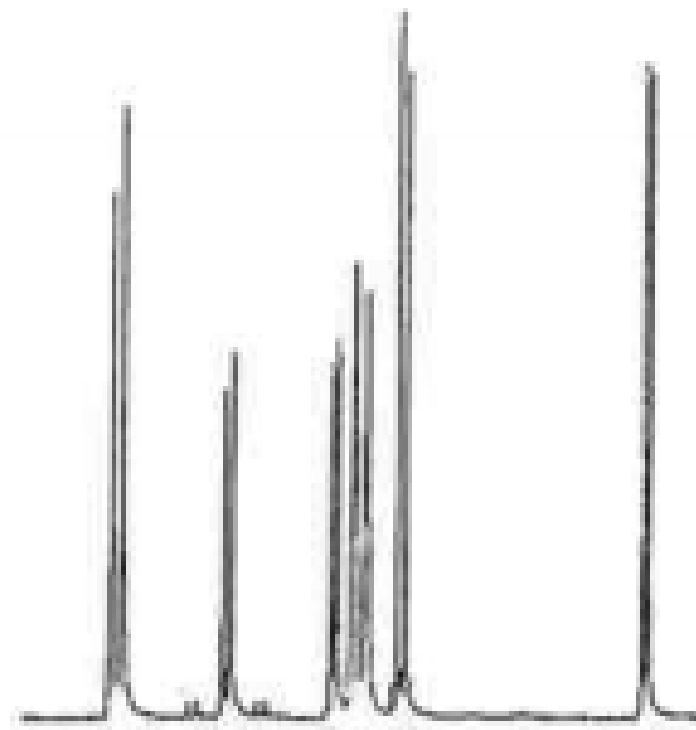


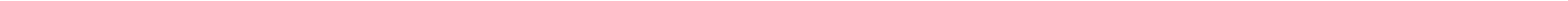


Duane $197-227$ RT: $2.23-2.51$ AV 31 NL: $6.25 E 5$

$\mathrm{T}:+$ p ESI Full ms [85.00-400.00]

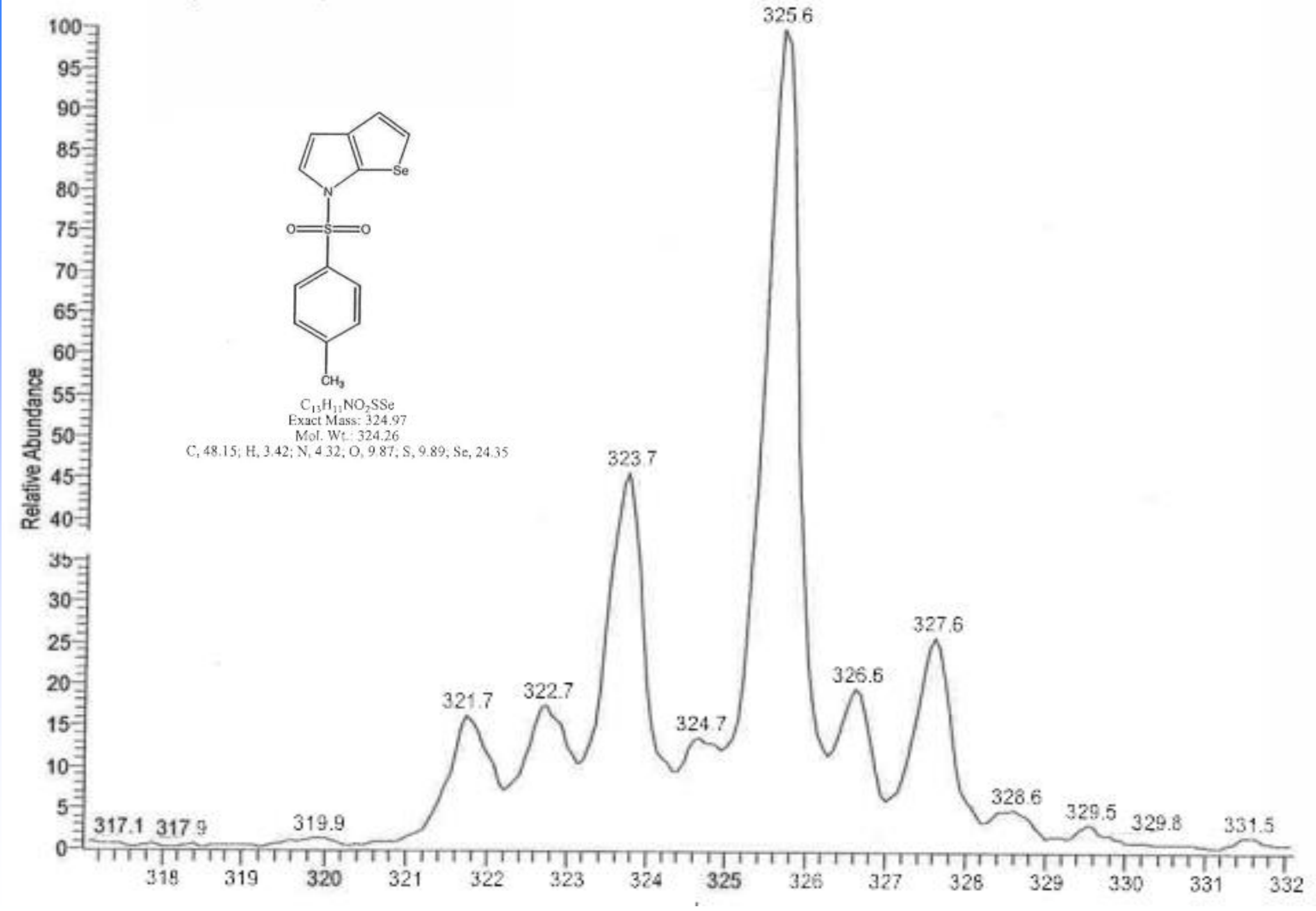


|

$\because \div$

- $7=0$

11

1

11 | |

a $y$

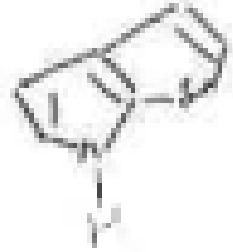

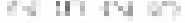

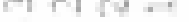
मान 5 का 1 I

Table 2.10. ${ }^{1} \mathrm{H}-\mathrm{NMR}$ Heterocycle data.
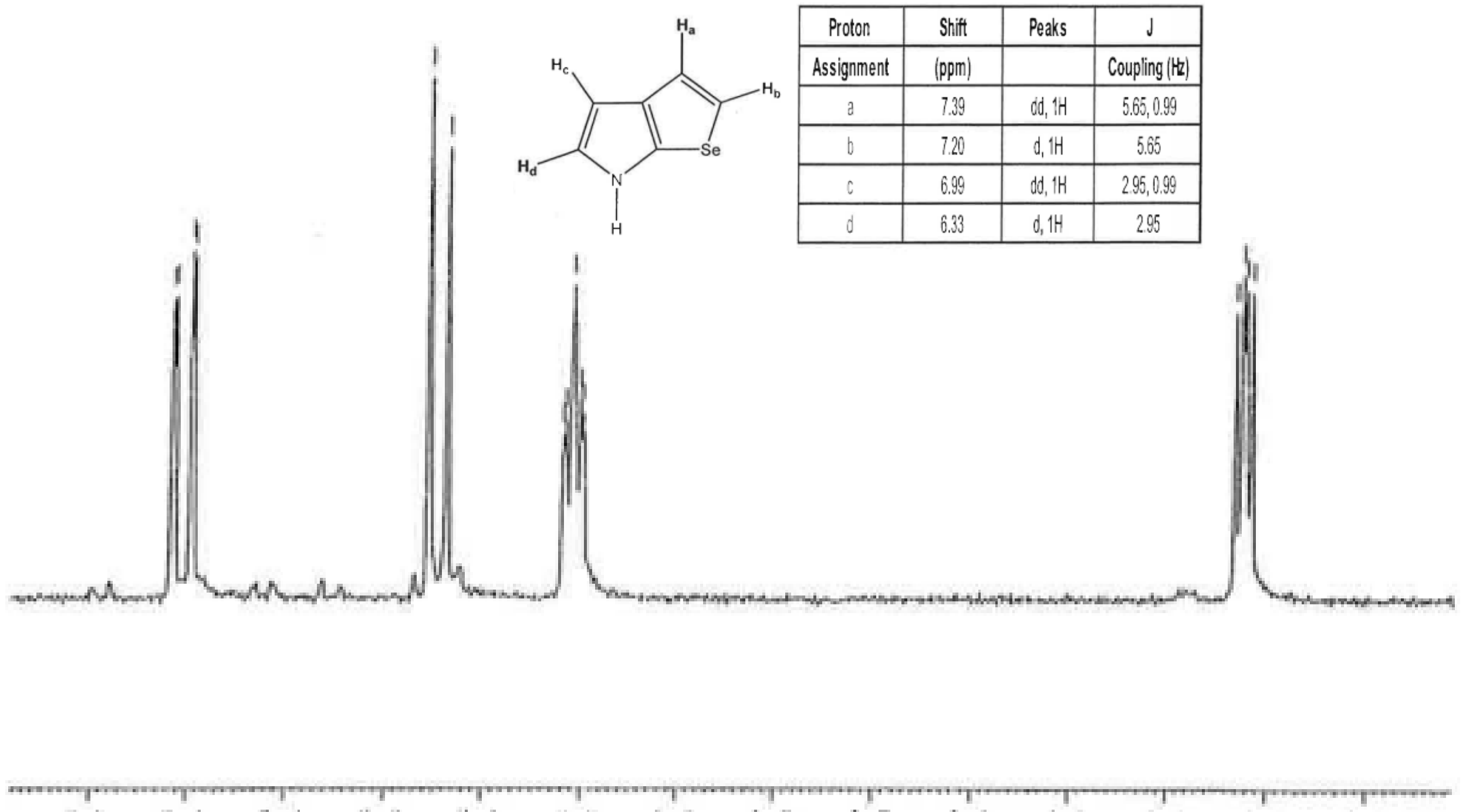


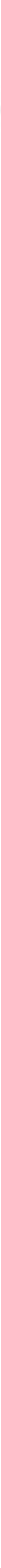




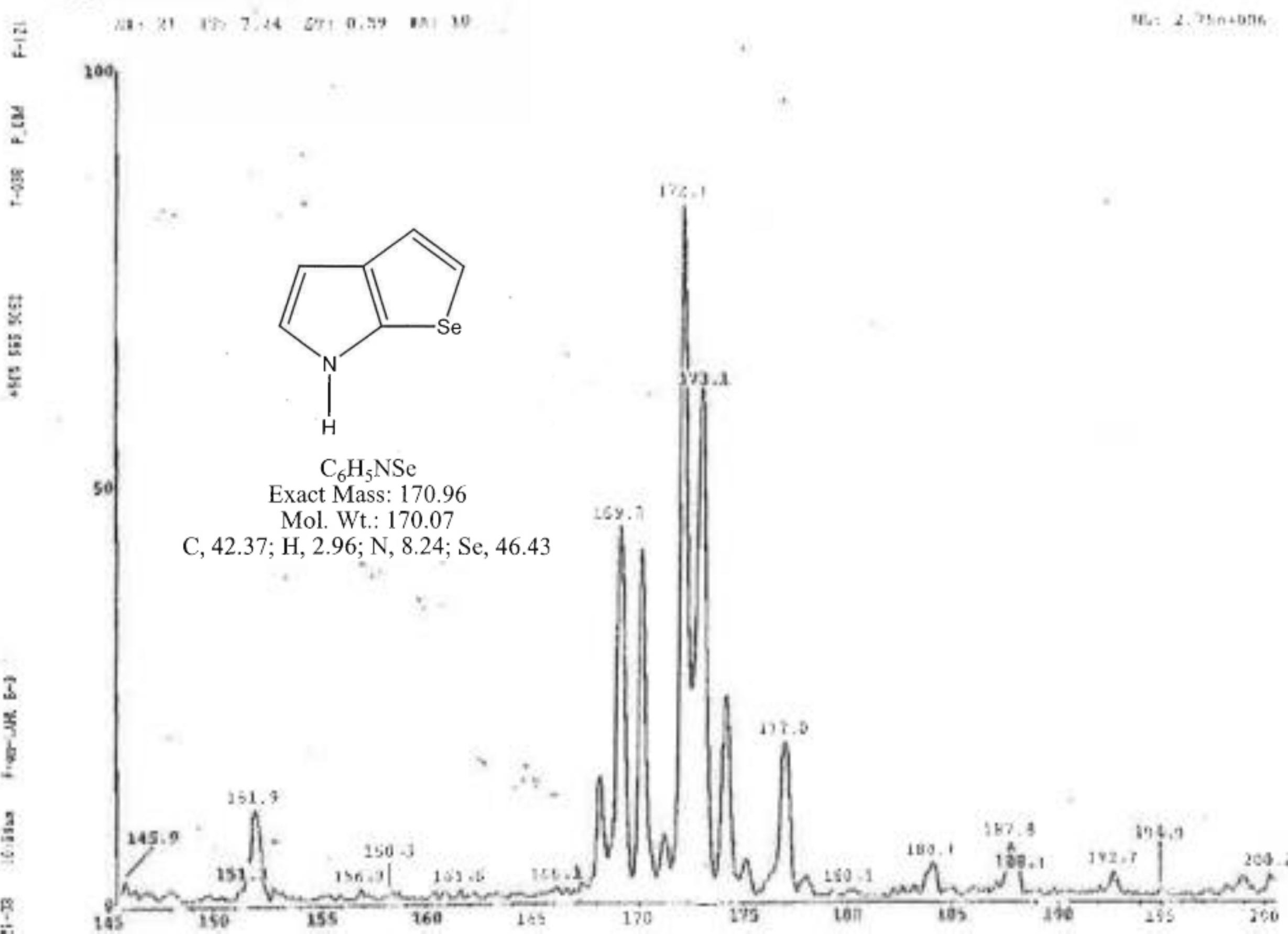




\section{Tryptophan Synthase}

- $\alpha_{2} \beta_{2}$ heterodimer

- $\alpha \beta \beta \alpha$ arrangement

$\alpha-28,700 \mathrm{Da}$

$\beta-43,000 \mathrm{Da}$

- Pyridoxal phosphate dependent.

- Catalyzes the last two steps in the biosynthesis of L-tryptophan.

- Accommodates many different indole derivatives.

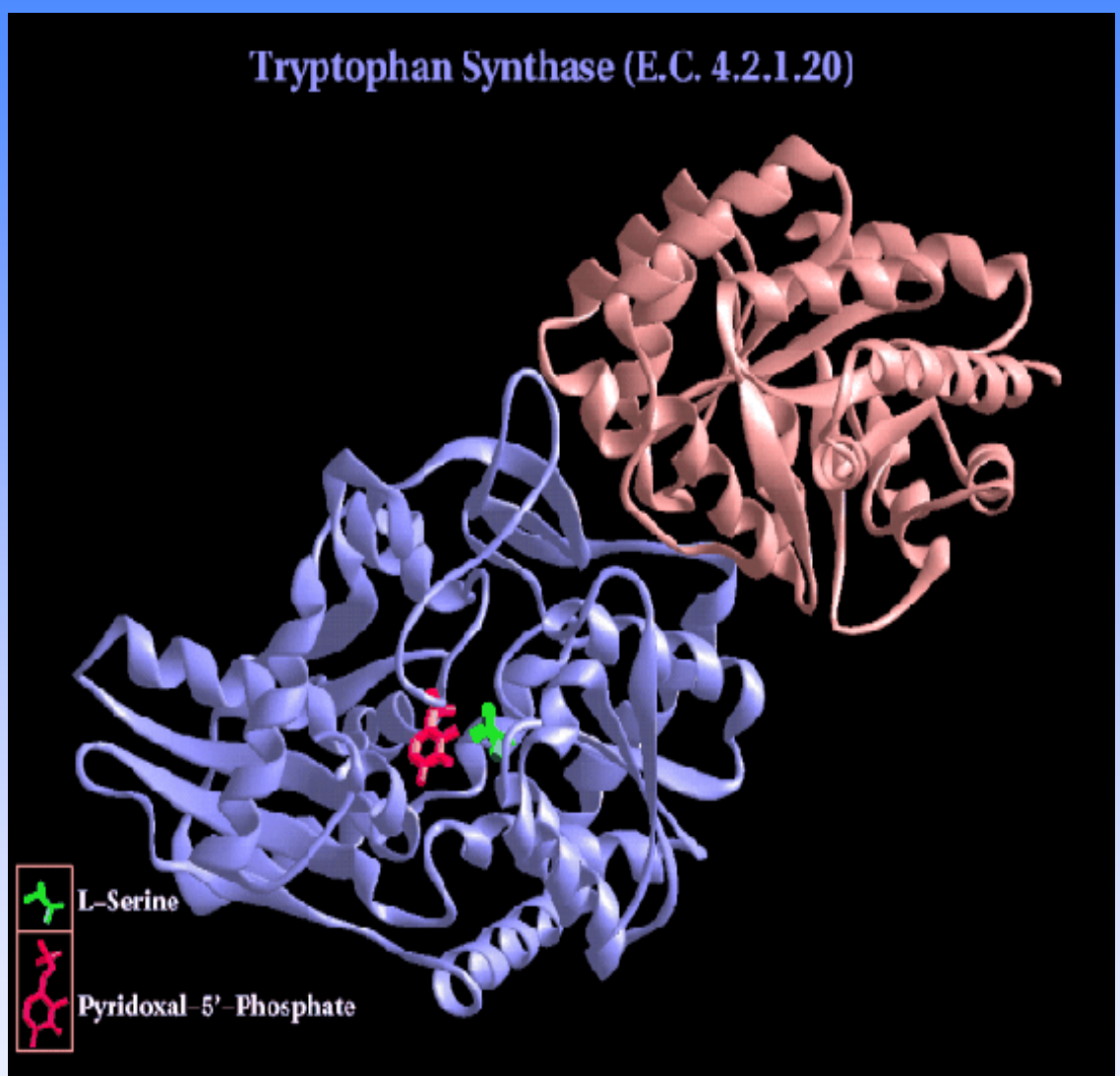

*picture from the protein data bank website 


\section{Enzymatic synthesis of [6,7]SeTrp}

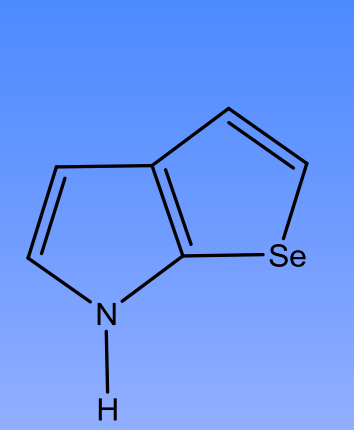

selenolo[2,3-b]pyrrole

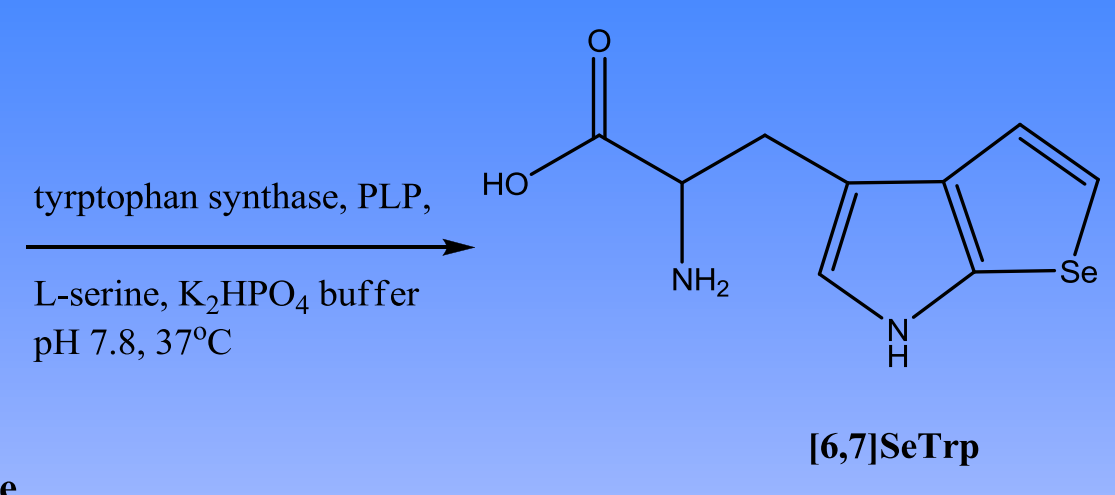

- $50 \mathrm{mg}(0.2 \mathrm{mmol})$ selenolo[2,3- $b]$ pyrrole (direct or in DMSO).

- $40 \mathrm{mg}$ (0.4 mmol) L-serine (labeled or unlabeled).

- $0.5 \mathrm{mg}$ pyridoxal-5-phosphate (PLP).

-1 ml (13 mg) S. typhimurium trypotophan synthase in $60 \mathrm{ml}$ degassed $0.1 \mathrm{M}$ Tris- $\mathrm{HCl}$ buffer $\mathrm{pH} 7.8$ (or $0.1 \mathrm{M} \mathrm{K}_{2} \mathrm{HPO}_{4}$ buffer, $\mathrm{pH}$ 7.8).

- $37^{\circ} \mathrm{C}$, dark, gently swirl, and monitor by TLC and ${ }^{13} \mathrm{C}-\mathrm{NMR}$.

- Purification (HPLC or reverse-phased cartridge). 


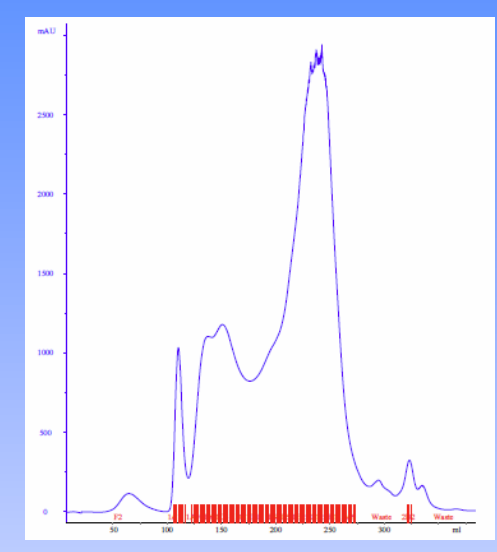

Fig. 9 Initial Size Exclusion Column

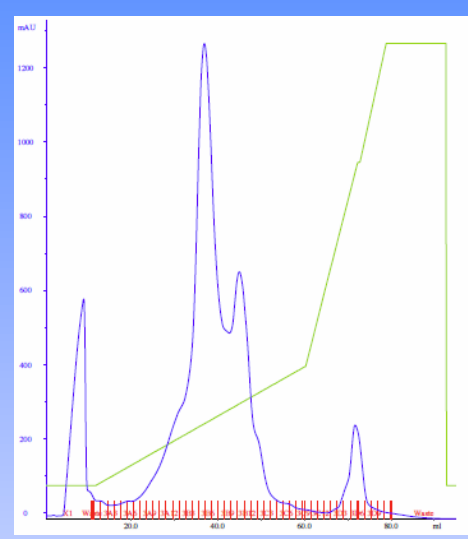

Fig. 10 Ion Exchange Column

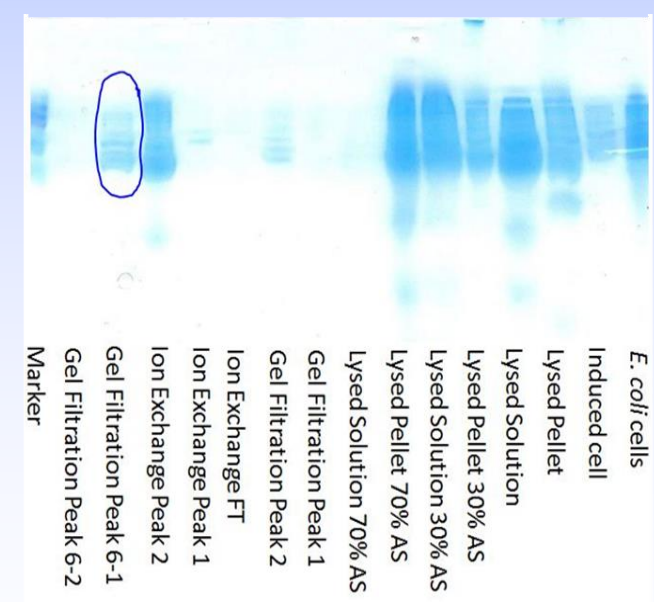

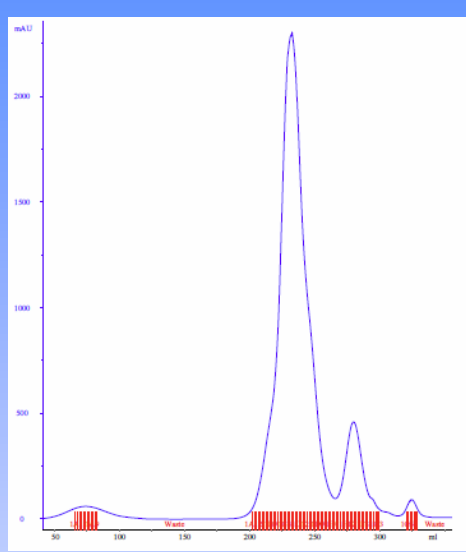

Fig. 11 Final Size Exclusion Column

Fig. 8 SDS Gel for TrpSyn purification 
Figure 4.13. $[\mathrm{M}+\mathrm{H}]{ }^{+13} \mathrm{C}$-labeled $[6,7] \mathrm{SeTrp}$.

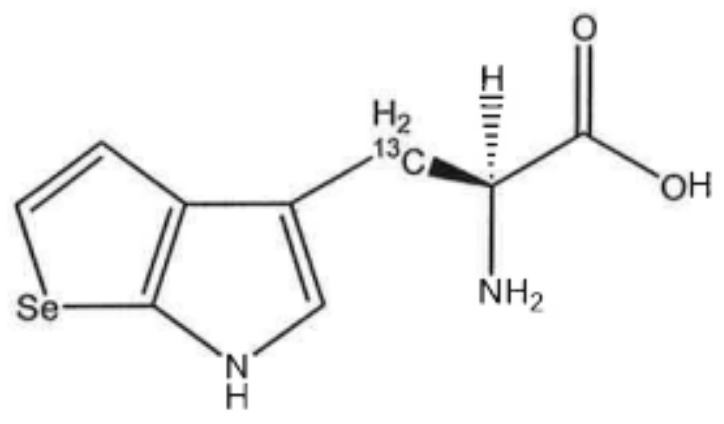

\section{${ }^{13}$ C-labeled \\ [6,7]SeTrp}

$\mathrm{C}_{8}{ }^{13} \mathrm{CH}_{10} \mathrm{~N}_{2} \mathrm{O}_{2} \mathrm{Se}$

Exact Mass: 258.99

Mol. Wt.: 258.14

C, 42.26; H, 3.90; N, 10.85; O, 12.40; Se, 30.59 
Table 4.1. ${ }^{1} \mathrm{H}-\mathrm{NMR}{ }^{13} \mathrm{C}-[6,7] \mathrm{SeTrp}$ data.
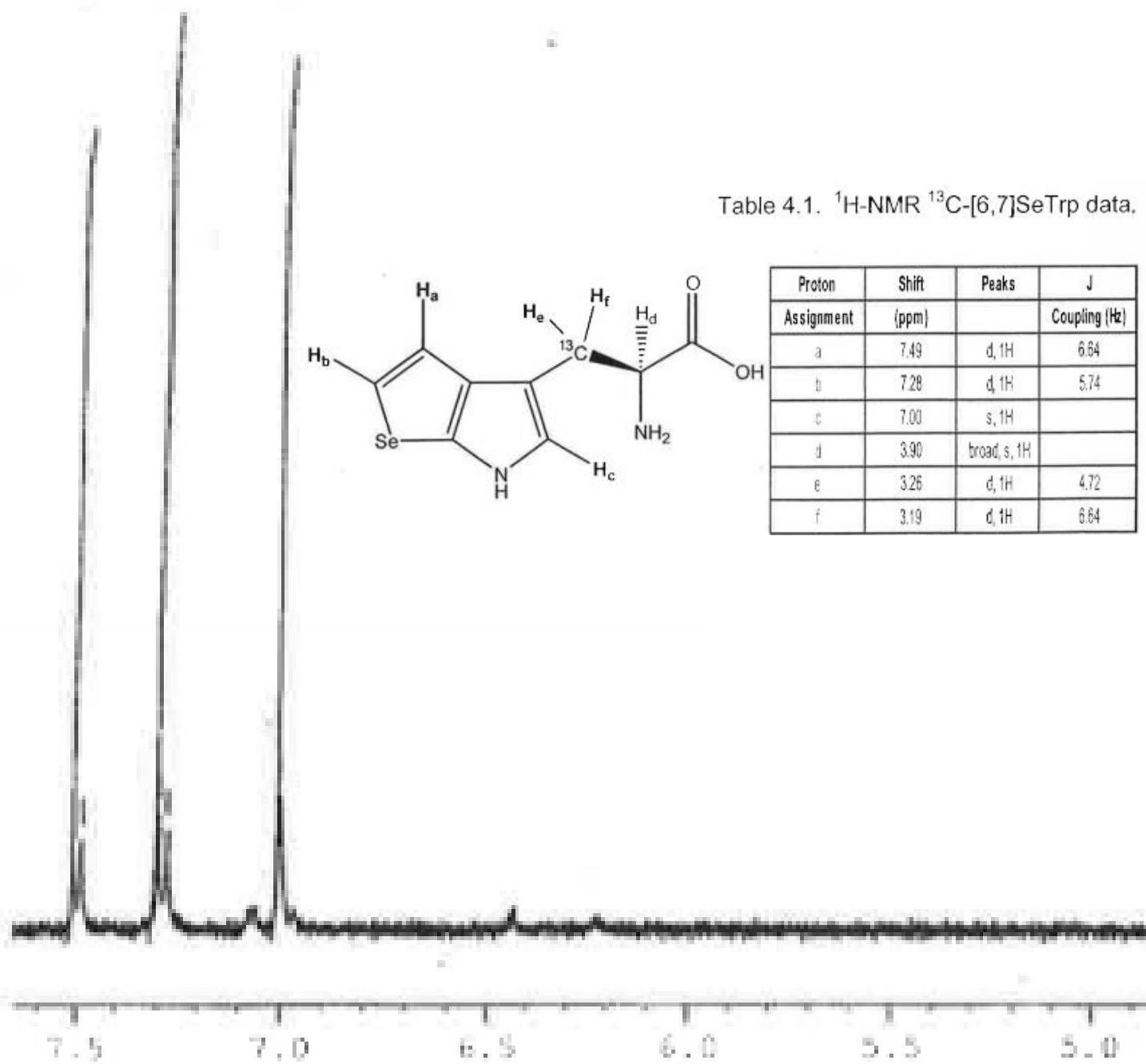

5.5

I. II

i $=$

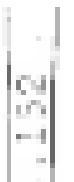




\section{[6,7]SeTrp-Dihydrofolate Reductase}

- Excellent test vehicle for unnatural amino acids

- $18 \mathrm{kDa}$

- 5 Trp and 5 Met residues

- $50 \mathrm{mg}$ pure [6,7]SeTrp-DHFR

- $100 \%$ bioincorporation via ICP and AA spectroscopy.

- No loss of activity over prolonged periods.

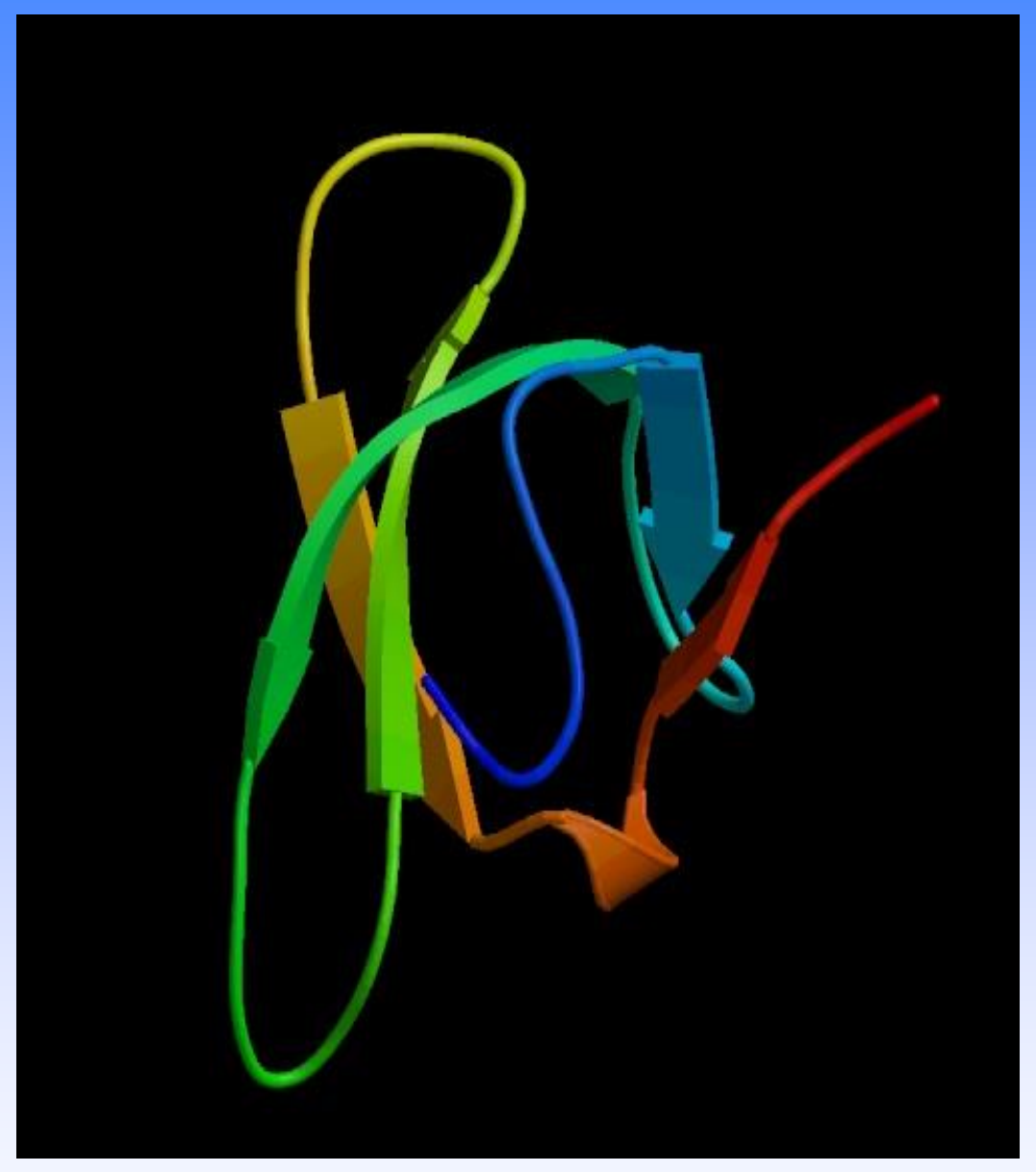

*picture from the protein data bank website 


\section{Bio-incorporation of [6,7]SeTrp into Lignan Peroxidase (LiP)}

- Extracellular heme protein.

- Cellulosic ethanol is a type of bio-fuel produced from biomass (lignocellulose).

- Non-food biomass is a viable raw material for bio-fuels.

- Need to remove lignin, which is as much as 25 wt \% of non-food biomass.

- Nature uses oxidative enzymes (peroxidases) to breakdown lignin.

- LiP has a catalytic Trp residue (Trp171) that is hydroxylated at the $\beta C$ position.

- Enhance activity by replacing Trp 171 with the more polarizable [6,7]SeTrp?

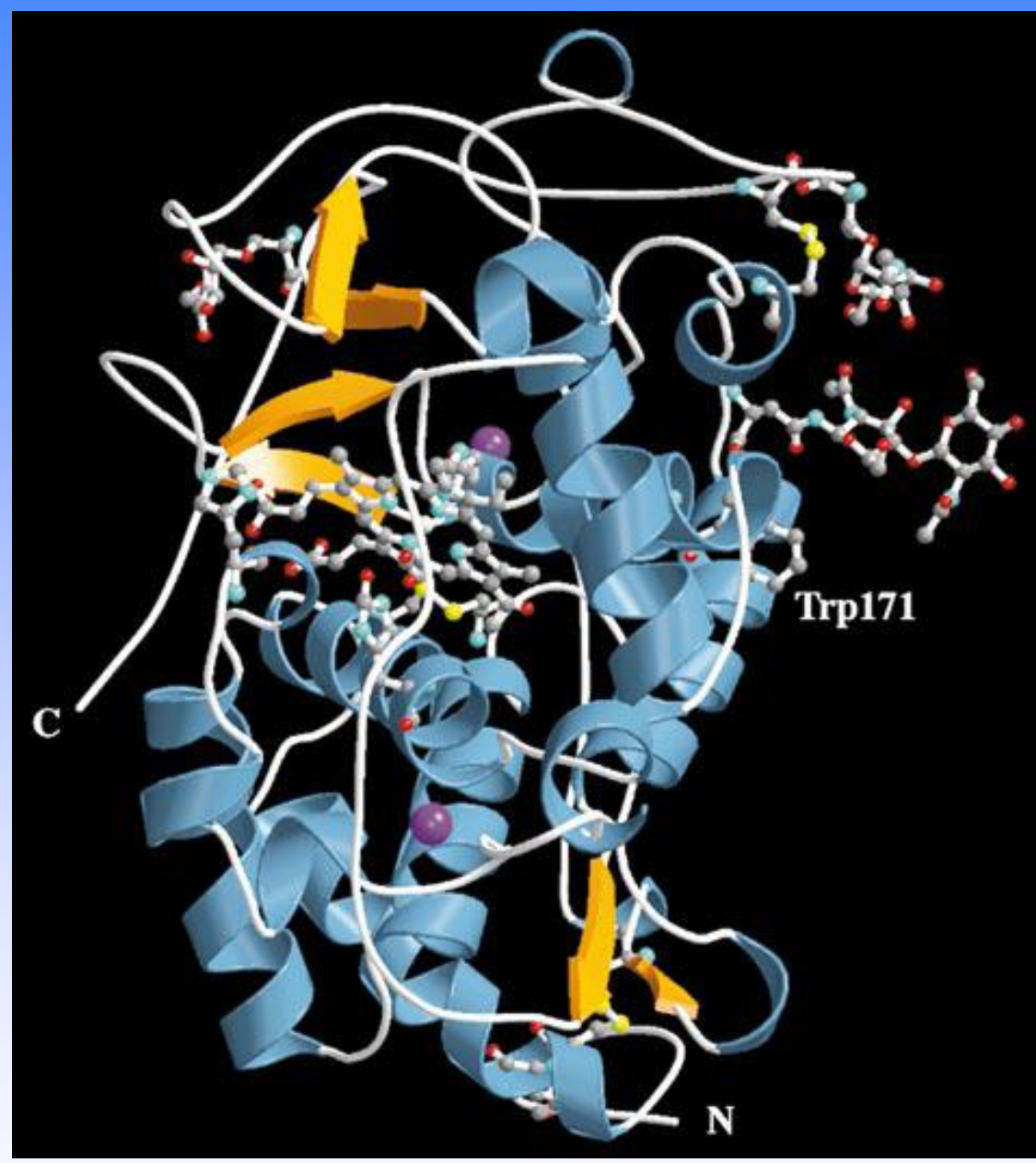

Piontek et al., 2001 Erbach et al., 2005 


\section{Tryptophan Auxotroph}

- We will create a Tryptophan auxotroph using a synthetic antisense RNA (asRNA) construct that will translationally block the expression of the Tryptophan Synthase (TryB).

- The asRNA will be expressed constitutively form the same expression vector expressing the Lignin Peroxidase (LipP).

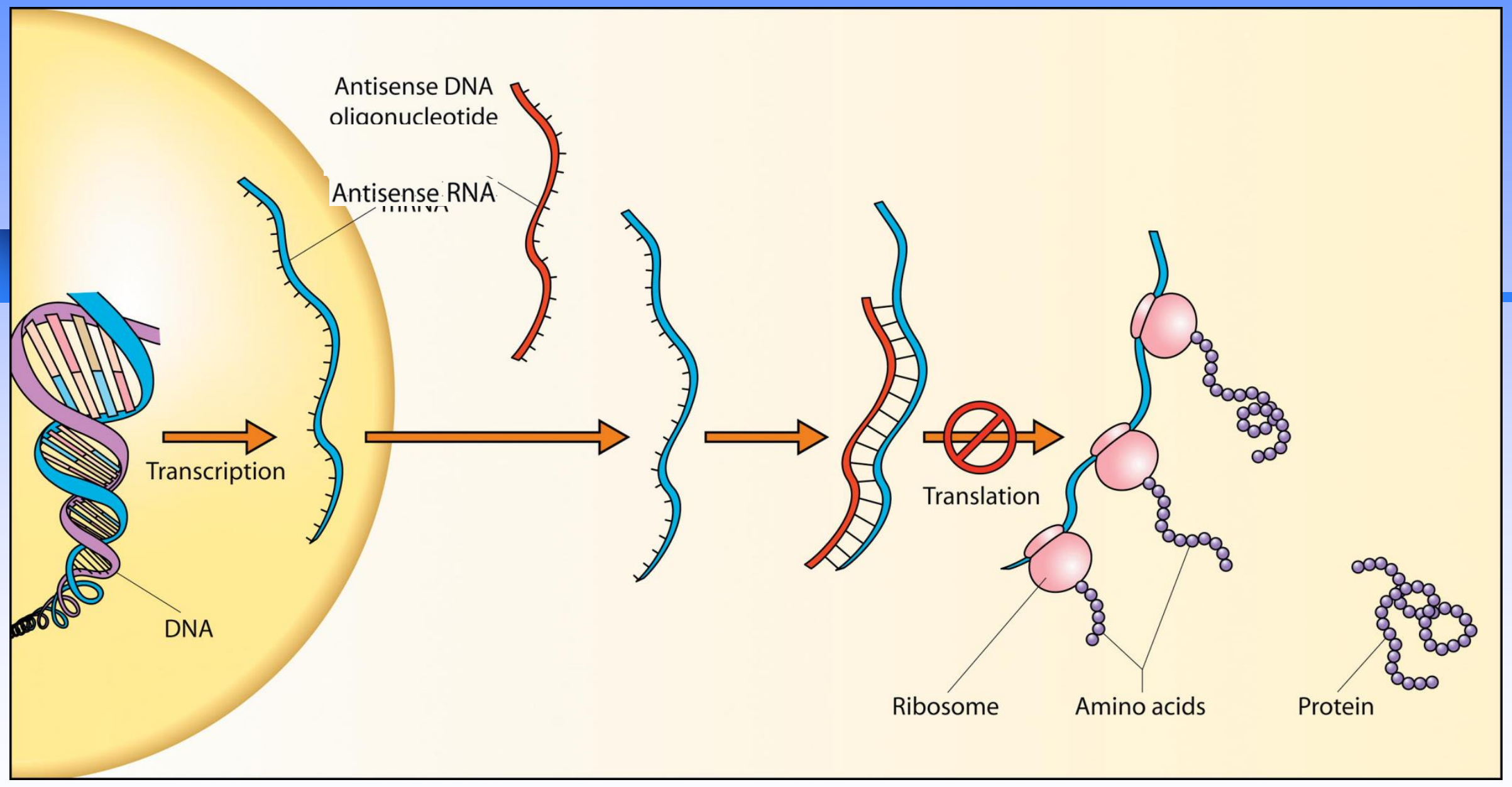

Picture from -

https://en.wikipedia.org/wiki/Sense_\%28molecular_biology\% 


\section{Conclusions}

$\bullet[6,7]$ SeTrp can be efficiently synthesized by these procedures and appears to be rather stable when protected from aeration and light.

-High-level incorporation of [6,7]SeTrp into recombinant DHFR with no loss of activity.

•[6,7]SeTrp and [6,7]TeTrp have the potential of becoming useful tools in the determination of three-dimensional protein structures.

-Stable isotope labeled [6,7]SeTrp and [6,7]TeTrp can be useful for the determination of structures and dynamics of proteins via NMR spectroscopy.

-Potentially useful for enhancing activity of LiP 
Acknowledgment This Project was made possible in part by funds received from the DOE Visiting Faculty Program.

Bioscience Division, Los Alamos National Lab.

Department of Chemistry and Physics, Belmont University.

\section{References}

- Bae, J. H., Alefelder, S., Kalser, J. T., Friedrich, R., Moroder, L., Huber, R., and Budisa, N., J. Mol. Biol. 2001, 309, 925-936.

- Boles, J. O., Tolleson, W. H., Schmidt, J. C., Dunlap, R. B., and Odom, J. D., J. Biol. Chem. 1992, 267, 22217-22223.

- Boles, J. O., Lewinski, K., Kunckle, M. G., Lebioda, L., Dunlap, R. B., and Odom, J. E., Nature Struct. Biol. 1994, 1, 283-284.

- Budisa, N., Karnbrock, W., Steinbacher, S., Humm, A., Prade, L., Neuefeind, T., Moroder, L., and Huber, R., J. Mol. Biol. 1997, 290, 616-623.

- Budisa, N., Minks, C., Medrano, F. J., Lutz, J., Huber, R., and Moroder, L., Proc. Natl. Acad. Sci. 1998, 95, 455-459.

- Hendrickson, W. A., Pahler, A., Smith, J. L., Satow, Y., Merritt, E. A., and Phizackerley, R. P., Proc. Natl. Acad. Sci. U.S.A. 1989, 86, 2190-2194.

- Müller, S., Senn, H., Gsell, B., Vettner, W., Baron, C., and Bock, A., Biochemistry. 1994, 33, 3404-3412.

- Welch, M., Phillips, R. S., Bioorg. \& Med. Chem. Lttrs. 1999, 9, 637-640.

- Farnier, S. S., Paulmier, C. Can. J. Chem. 1978, 56, 1978. See also, Silks, L. A., Li, Z., 216th ACS National Meeting, Boston. Title "A Convenient Synthesis of Thieno-, seleno[2,3-b] pyrroles from 